\title{
Crimean-Congo hemorhagic fever: exceptional epidemic of viral hemomhagic fever in Turkey
}

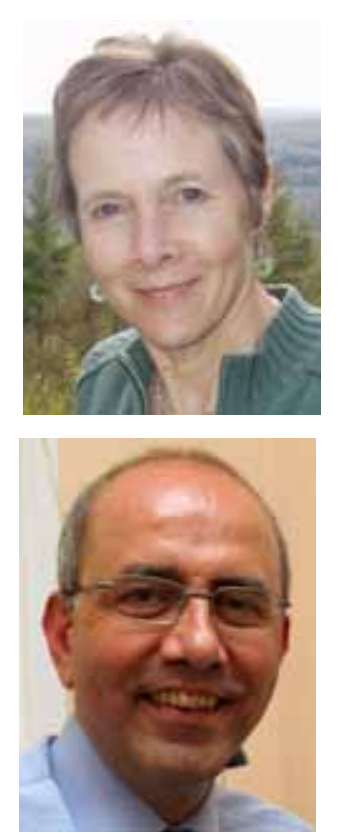

\section{Sarah Randdpht \& Önder Ergönül}

${ }^{\dagger}$ Author for correspondence D epartment of Zoology, U niversity of 0 xford, South Parks Road, 0 xford, OX1 3PS, UK

Tel.: + 44186527 1241; Fax: +44 186527 1240; sarah.randolph@zoo.ox.ac.uk

future part of $\mathrm{fsg}$
'At present, there is little control of this fearsome infection, whose symptoms of extensive

hemorhage are tailor-made for onward transmission.'

An exceptional epidemic

The eyes of the world are, or at least should be, focused on Turkey to witness and try to understand an exceptional epidemic of a viral hemorrhagic fever (VHF) occurring now, despite the country's good scientific, medical, public health and surveillance infrastructure. C rimean-C ongo hemorrhagic fever (CCHF), caused by a ticktransmitted $\mathrm{N}$ airovirus in the family Bunyaviridae, is holo-endemic in more than 30 farflung countries, principally in southern, western and (recently) eastern Africa, Europe around the eastern M editerranean and the Black Sea, the $M$ iddle East and Asia as far east as Pakistan and western C hina, and north into Russia as far as the $50^{\circ}$ latitude. 0 wing to their high case-fatality rate $(30-50 \%$, and even as high as $80 \%$ for some VH Fs), Lassa fever, Ebola and M arburg are the best-known and most feared VH Fs, despite their relatively low incidence, while CCH F is virtually unknown outside the circle of experts, many of whom met in Istanbul in June 2008. Typically, at most a few dozen human cases are confirmed each year in the affected countries, but annual spikes three to four-times higher occur sporadically, with no pattern apparent from the short time series of reliable annual data available, and no clear synchrony between countries (Figure1). Presumably, a combination of factors, both intrinsic and extrinsic to the biology of the system, may trigger a spike. In Kosovo, for example, there were outbreaks in 1991-1992, 1995 and 2001 [1], some of which may have been associated with military and political conflict and consequent societal disruption and population movement leading to greater exposure to ticks.

Turkey is different. CCHF was unknown before 17 cases were confirmed in 2002, but since then case numbers have increased exponentially year on year to reach 717 cases in 2007 and over 600 in the first half of 2008. The only consolation is that Turkey also differs in the virulence of the viral strain, with a case- fatality rate of $5 \%$ compared with an average of $20-30 \%$ in other countries [2]. By no means may all of this increased incidence be explained away by heightened awareness in Turkey and diagnosis of more subclinical cases; all reported cases were confirmed by laboratory diagnosis, whose specificity has increased as laboratory capacity has improved in response to the outbreak. Awareness is as likely to cause a decrease in incidence through self-protection and avoidance of exposure to infection. Indeed, many small traders' stalls in the heart of Istanbul are festooned with (inaccurate) pictures of ticks advertising protective sprays.

\section{Multiple routes of transmission}

Explanations of any epidemic depend on a full understanding of the biological basis of transmission routes and, therefore, the conditions underlying the epidemiological dynamics. For Europe's most significant tick-borne virus, tickborne encephalitis (TBE) virus, the connection between the cellular basis of transmission, the ecological specificity of the tick vector and reservoir hosts and the climatic determinants of the continental distribution of foci have been revealed in great detail over the past decade. In contrast to this, the identity of the key players in CCHF virus transmission are not yet fully known. Hyalomma tick species, particularly $\mathrm{H}$. marginatum marginatum, have long since been implicated because their distribution is correlated with that of $\mathrm{CCHF}$, but their specific biology and host relations weaken their potential as vectors [3], and other species may be needed to play complementary roles. Traditionally, medium-sized mammals such as hares have been thought of as significant reservoir hosts [4], but new results implicate ground-dwelling birds in Turkey [Vatansever $Z$, Unpublished Data]. The tick population, however, depends on larger hosts such as cattle that feed the reproductive adults. The possibility, even probability, of a complex network of overlapping tick and host species, each playing a vital role in the maintenance of $\mathrm{CCHF}$ amongst wildlife, is typical for tick-borne disease 


\section{Figure 1. Annual numbers of laboratory confirmed cases of Crimean-Congo hemorrhagic fever in southeast Europe and Iran since 1995.}
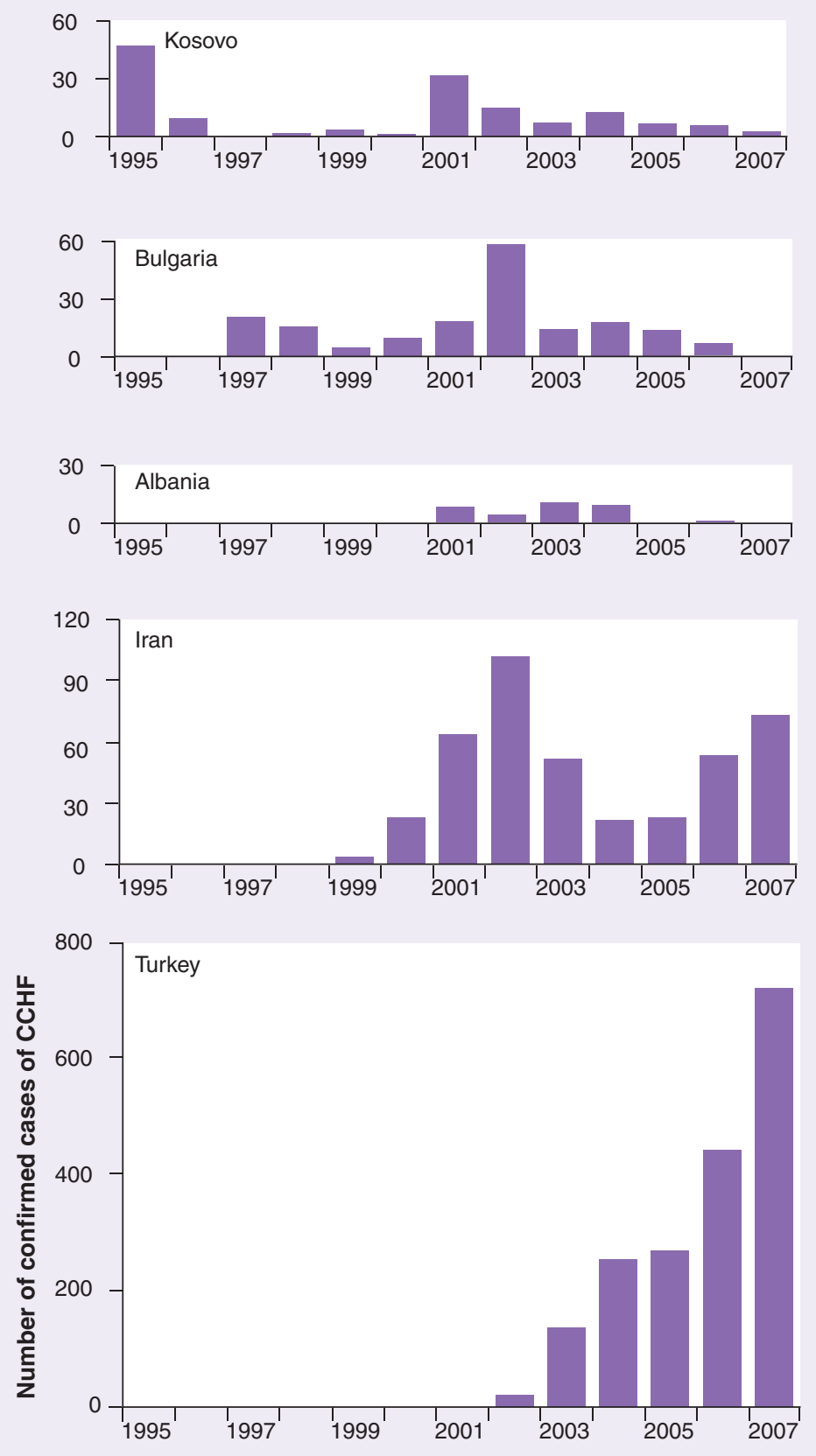

systems and significantly complicates any attempts at full quantitative explanations and dynamical predictions.

Routes of human exposure are also diverse. In South Africa, amongst 180 cases from 1981 to 2006, infection via direct contamination with body fluids of infected animals was almost as common as through bites by host-seeking infected adult ticks or contact with crushed ticks feeding on livestock, a particular hazard while handling animal carcasses and preparing hides. H umans themselves may pass on the virus, allowing nosocomial infections. From this it is clear how societal disruption may exacerbate the risk of infection abruptly if normal practices of meat preparation and human hygiene breakdown.

Where did CCHF in Turkey come from? The most common scapegoats blamed for the sudden appearance of zoonotic (i.e., wildlifemaintained) infections are migratory birds. The geography of the outbreak in Turkey, however, argues against this. It started in 2002 south of the Black Sea in northeast Anatolia, principally in the districts of Tokat, Sivas and Yozgat [5], but by 2006 clinical cases were distributed along a narrow band through the northern portion of the country, from the Georgian border in the east and moving ever closer to Istanbul in the west [6]. If introductions by birds are common enough to account for the wide global distribution of $\mathrm{CCHF}$ and also these new foci in Turkey, the question arises: why now? Alternatively, if such introductions are rather rare events, the question is how did CCHF become so widespread so quickly in Turkey and why now? Answers to both questions would imply altered conditions, suddenly and over wide areas, to increase the likelihood of either introduction or establishment, or both. The same would be true of introductions via infected livestock, most likely from Kosovo and/or southwest Russia according to the phylogenetic clustering of the Turkish isolates [5].

More likely is that these emergent foci are exactly that, emerging above the surface from pre-existing enzootic cycles hitherto undetected below the surface. For zoonotic diseases, endemic risk foci are commonly defined on the basis of recorded human cases, the tips of the zoonotic iceberg that are implicitly assumed to map neatly on top of the submerged bulk [7]. Reports in 1980 of serological evidence of the existence of $\mathrm{CCHF}$ in Turkey illustrates the more realistic scenario that these enzootic cycles are likely to be far more widespread than reveal ed by human cases, able to spread gradually and increase while remaining below the surface, but ready to pop up above the surface if conditions change. $O$ ne change is an increase in risk, in the form of more abundant infected ticks through increased enzootic transmission potential for one reason or another. Another change, not necessarily alternative and possibly even 
driven by the same extrinsic factors, is an increase in human exposure to risk. In the case of $\mathrm{CCHF}$, as human-human transmission is possible, the former could itself lead to the latter, but not to the same extent as with a wholly human transmission cycle such as for malaria. The question then is what has changed in Turkey to kickstart this emergence, and moreover to maintain it rather than to let it subsideas in other neighboring countries where $\mathrm{CCH} F$ is endemic.

\section{'Capac ity building a mongst sc ientists and public health personnel is desperately needed if the ecology and epidemiology of CCHF is to be better understood and thereby controlled.'}

Possible causes: climate change or not Just as migratory birds are the commonest, but inadequate, explanation for introductions of exotic pathogens, so climate change is the current ubiquitous explanation for increased incidence of infections of many sorts. As ticks are obviously subject to seasonal climate effects, and $H$ yalomma ticks are better adapted to surviving in warm dry conditions than are many other ticks, it is reasonable to suggest that recent climate events may have promoted outbreaks of CCHF. There was a step increase in temperatures, particularly during July and August, in 1998 in Turkey (compared with a similar step in 1990 in the Balkans, and in spring temperatures in 1989 in most of the rest of Europe [8]), with no trends either before or after this sudden change. This crude pattern, however, cannot indicate causality without a detailed analysis of the climatic conditions associated with $\mathrm{CCH} \mathrm{F}$ presence and local trends in these specific factors. O nly if disease emergence in new places or increases in incidence, for example, are strictly consistent in time and space with biologically relevant environmental changes may we impute causality. Conversely, uniform climate change patterns but heterogeneous epidemiological patterns indicate that there must be other crucial causal factors [8]. This is analogous to Koch's postulates, which demand absolutely consistent associations between the presence of a pathogen and evidence of infection. Hitherto, no such consistency has been found either on a small spatial scale within Turkey or on broader scales in southeast Europe.

Instead, taking lessons from recent analyses of the causes of the T BE upsurge in 1993 in central and eastern Europe [9], there are reasons to believe that we are faced with a complex network of environmental and human factors. These may operate differentially over large heterogeneous regions, may each change independently while being indirectly linked, and may act synergistically or antagonistically on the enzootic transmission cycles and/or degree of human exposure. In the case of TBE, many of the factors were the unforeseen consequences of the socioeconomic transition arising from political independence [10]. They involved abiotic and biotic environmental changes of the sort that could increase the abundance of infected ticks, and changes in human activities associated with increases in both poverty and wealth resulting in greater contact between people and tick-infested forests. There are considerable analytical problems in dealing quantitatively with such disparate factors, but there are qualitative precedents dating from the very first recognition of $\mathrm{CCHF}$ in Crimea in 1945. According to the late $\mathrm{H}$ arry H oogstraal, elder statesman amongst tick-borne disease specialists, after the occupation of Crimea during World War II, disruption of normal agricultural activities and the abandonment of hare hunting allowed fields to become overgrown with weeds and occupied by high densities of hares, thereby improving both the abiotic and biotic conditions for ticks [4]. When susceptible Soviet troops re-occupied the region in 1944, a major epidemic occurred, with 200 cases and $10 \%$ mortality. Exactly what changes may have precipitated the outbreak of CCH F in Turkey from 2002 are not yet known. Interestingly, however, an explanation similar to the one mentioned previously has been suggested: fields in the Anatolian region had been abandoned for hunting and pasturing between 1995 and 2001 because of terrorist activities there, allowing an increase in small and large mammals such as hares and pigs, and thus potentially an increase in infected ticks [2]. Another possibility suggested by Zati Vatan sever [Vatansever Z, Unpublished D ata], who is currently studying natural tick ecology and enzootic CCH F transmission dynamics, is the reduction in agricultural activity as people migrate to the towns, leaving cattle to graze on increasingly bushy land where ticks thrive and will survive and reproduce better with more hosts to feed on. Such migration, however, has been going on for the past 40 years in Turkey, so careful analysis of the timing and extent of these changes will be necessary to substantiate this idea. If proved correct, it offers a simple method of control: reverse this grazing trend. 
Urgent need for capacity building

At present, there is little control of this fearsome infection, whose symptoms of extensive hemorrhage are tailor-made for onward transmission. There is no vaccine, and the clinical response consists mostly of hospital-based support. The effectiveness of treatment with ribavirin, an inhibitor of replication of a wide range of RN A viruses, remains unproven while patients typically present themselves in an already advanced state of the disease [11].

Capacity building amongst scientists and public health personnel is desperately needed if the ecology and epidemiology of CCH F is to be better understood and thereby controlled. Field studies take time and are labor intensive; the more replicates in different places and over long periods, the more the natural picture can be built up and explanations progress from anecdote to evidence. CCHF is an issue of burning urgency, not because of the current Europo- and Americo-centric views that this virus poses a bioterrorism threat, nor that the 'West' is at danger of natural invasion, but because many people within established endemic regions are already at risk, which, in the case of Turkey, appears to be expanding and increasing. It is not enough to fly in expatriate experts; the expertise must be built up within each country, in each of which there are already individuals with great knowledge and experience, but too few of them. The recently launched EU -funded Arbo-Zoonet
Coordination Action Project, which focuses on $\mathrm{CCH} \mathrm{F}$, West $\mathrm{N}$ ile fever and Rift Valley fever, is by no means unique in its membership: $85 \%$ of the consortium and its associates are from western Europe, with one each from Slovenia, Romania, Iran and China, and two each from Turkey, South Africa and Senegal. W hile this is not surprising, given whose taxes fund most such discussion and data-sharing networks, nevertheless the philanthropic value, not to mention the benefits in supposedly protecting the EU, would be greatly enhanced if more were invested in countries where these infections are endemic.

\section{Acknowledgements}

The authors thank the European Society of Clinical M icrobiology and Infectious Diseases (ESCMID), the Turkish Society of Clinical Microbiology and Infectious Diseases (KLIM IK) and the Italian Society for Virology for their support of a recent conference on viral hemorrhagic fevers at which these i deas ger minated.

Financial \& competing interests disclosure The authors haveno relevant affiliations or financial involve ment with any organization or entity with a financial interest in or financial conflict with the subject matter or materialsdis cussed in the manuscript. This includes employment, consultancies, honoraria, sock ownership or options, expert testimony, grants or patents received or pending, or royalties

No writing assistance was utilized in the production of this manuscript.
Bibliography

1. Avsic-Zupanc T: Epidemiology of Crimean-C ongo hemorrhagic fever in the Balkans. In: Crimean-C ongo H emorrhagic Fever: A Global Perspective. Ergonul O, W hitehouse CA (Eds). Springer, D ordecht, The N etherlands, 75-88 (2007).

2. Ergönül Ö: C rimean-C ongo hemorrhagic fever. Lancet Infect. D is. 6, 203-214 (2006).

3. Randolph SE, Rogers D J: Ecology of tick-borne disease and the role of climate. In: Crimean-C ongo $\mathrm{H}$ emorrhagic Fever: A Global Perspective. Ergonul 0 , Whitehouse CA (Eds). Springer, D ordecht, The $N$ etherlands, 167-186 (2007).

4. H oogstraal $H$ : The epidemiology of tick borne C rimean-C ongo hemorrhagic fever in Asia, Europe and Africa. J. M ed. Entomol. 15, 307-417 (1979).

5. Karti SS, $\mathrm{O}$ dabasi Z, Korten V: C rimeanCongo hemorrhagic fever in Turkey. Emerg. Infect. Dis. 10, 1379-1384 (2004).
6. Vatansever Z, U zun R, Estrada-Pena A, Ergonul 0 : Crimean-Congo hemorrhagic fever in Turkey. In: Crimean-Congo H emorrhagic Fever: A Global Perspective. Ergonul 0 , W hitehouse CA (Eds). Springer, D ordecht, The N etherlands, 59-74 (2007).

7. Randolph SE, Šumilo D: Tick-borne encephalitis in Europe: dynamics of changing risk. In: Emerging Petsand Vector-borneD iscase in Europe. Takken W, Knols B (Eds). Wageningen Academic Publishers, Wageningen, The N etherlands, 187-206 (2007).

8. Šumilo D, Asokliene L, Bormane A, Vasilenko V, Golovljova I, Randolph SE: Climate change cannot explain the upsurge of tick-borne encephalitis in the Baltics. PLOS ONE 2, e500 (2007).

9. Šumilo $D$, Bormane $A$, Asokliene $L$ et al.: Socio-economic factors in the differential upsurge of tick-borne encephalitis in Central and Eastern Europe. Rev. M ed. Virol. 18, 81-95 (2008).
10. Randolph SE: Tick-borne encephalitis incidence in Central and Eastern Europe: consequences of political transition. M icrobes Infect. 10, 209-216 (2008).

11. Ergönül 0 : Treatment of $C$ rimean-C ongo hemorrhagic fever. Antivir. Res. 78, 125-131 (2008).

\section{Affiliations}

- Sarah Randolph, Professor D epartment of Zoology, U niversity of 0 xford, South Parks Road, O xford, OX1 3PS, U K Tel.: + 44186527 1241; Fax: +44 186527 1240; sarah.randolph@zo0.ox.ac.uk

- Ö nder Ergönül, Associate Professor Infectious D iseases \& Clinical M icrobiology $D$ epartment, University of $M$ armara, School of M edicine, Altunizade, Istanbul, Turkey Tel.: + 90535815 2741; Fax: + 90216327 4142; onderergonul@yahoo.com 